Supplement of Geosci. Model Dev., 11, 5189-5201, 2018

https://doi.org/10.5194/gmd-11-5189-2018-supplement

(C) Author(s) 2018. This work is distributed under

the Creative Commons Attribution 4.0 License.

(c) (1)

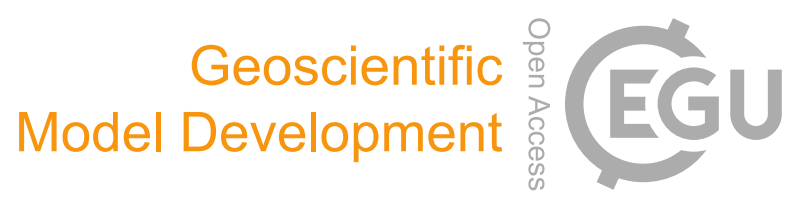

Supplement of

\title{
Automatic tuning of the Community Atmospheric Model (CAM5) by us- ing short-term hindcasts with an improved downhill simplex optimization method
}

Tao Zhang et al.

Correspondence to: Minghua Zhang (minghua.zhang@stonybrook.edu) and Wei Xue (xuewei@ mail.tsinghua.edu.cn)

The copyright of individual parts of the supplement might differ from the CC BY 4.0 License. 

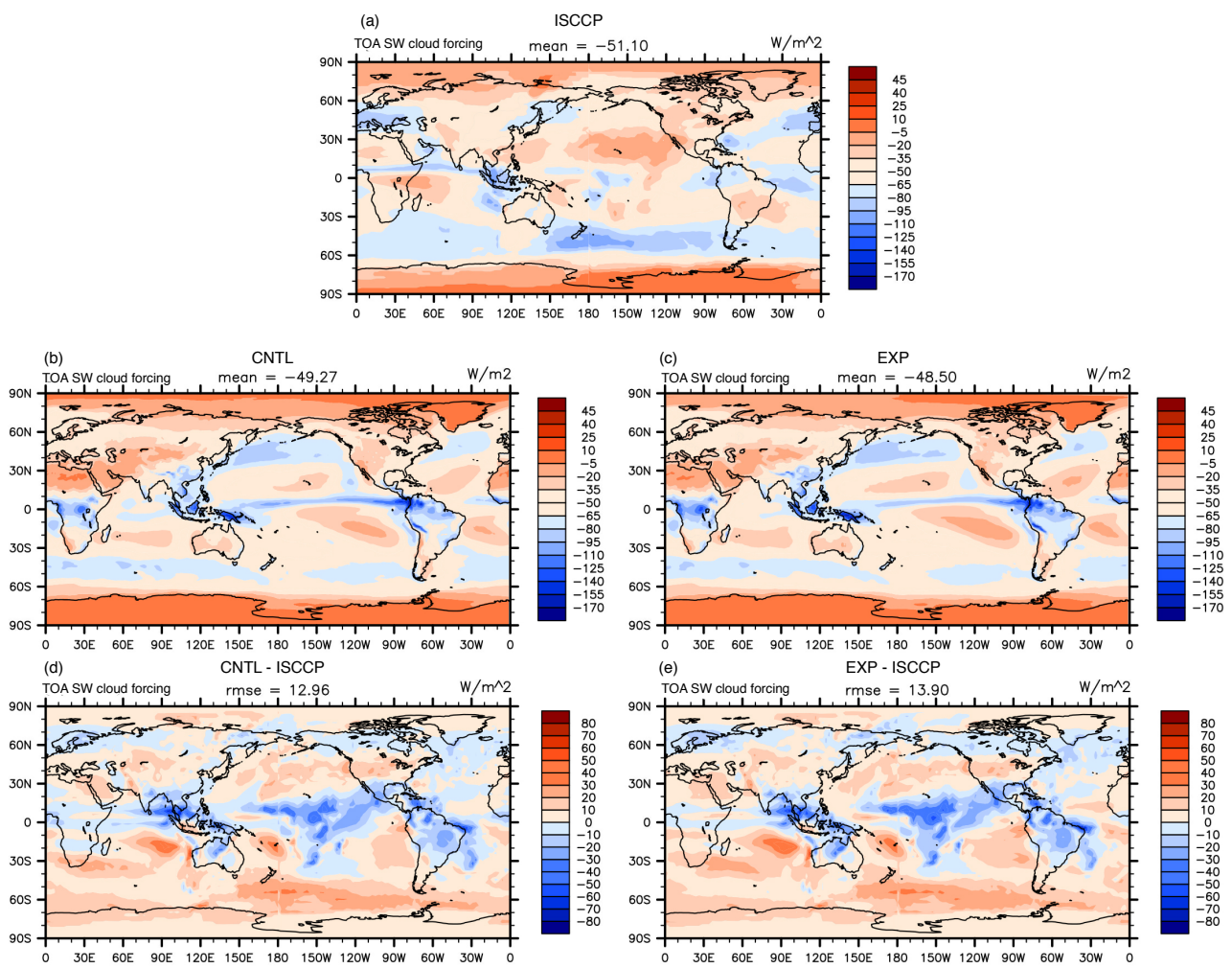

738 Figure A1. The spatial distribution of TOA SW cloud forcing in (a) observation, (b)

CNTL, (c) EXP, (d) CNTL minus observation, (e) EXP minus observation. 

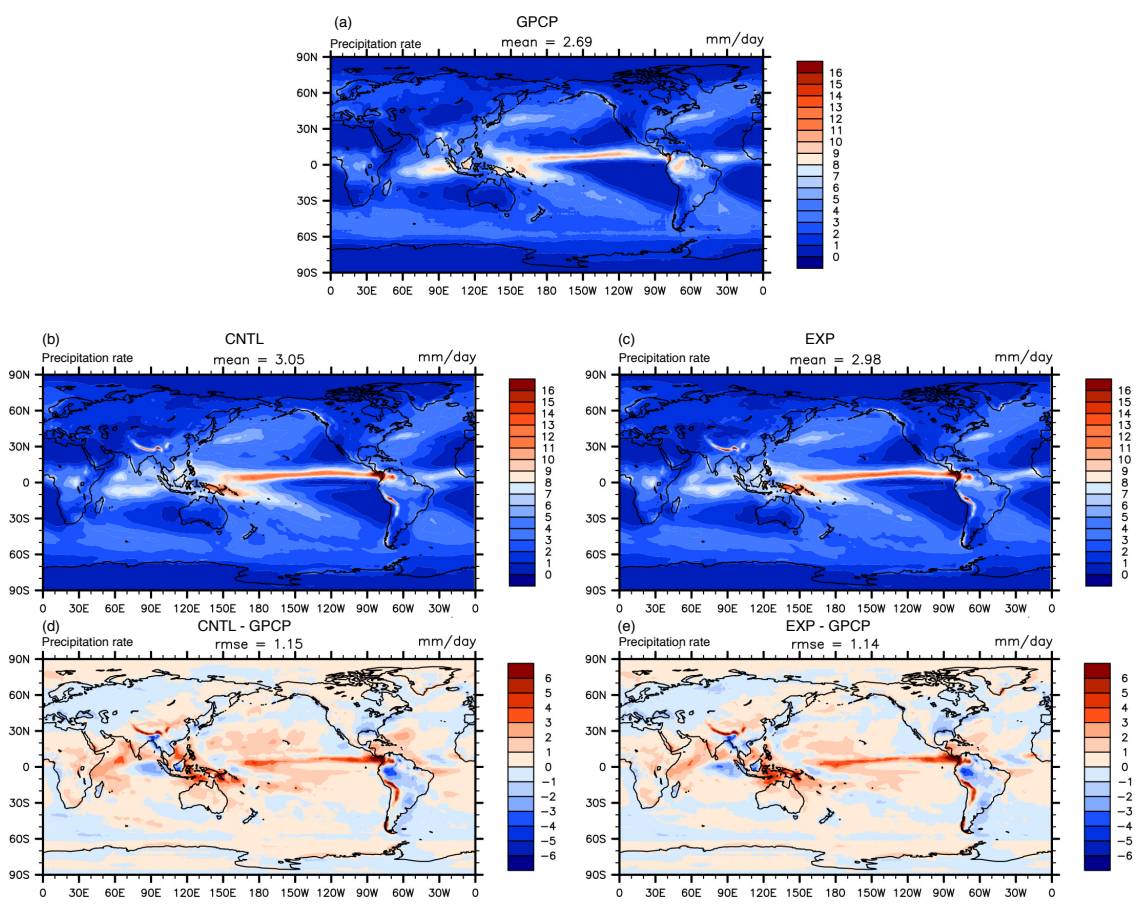

Figure A2. The spatial distribution of precipitation rate in (a) observation, (b) CNTL,

(c) EXP, (d) CNTL minus observation, (e) EXP minus observation. 

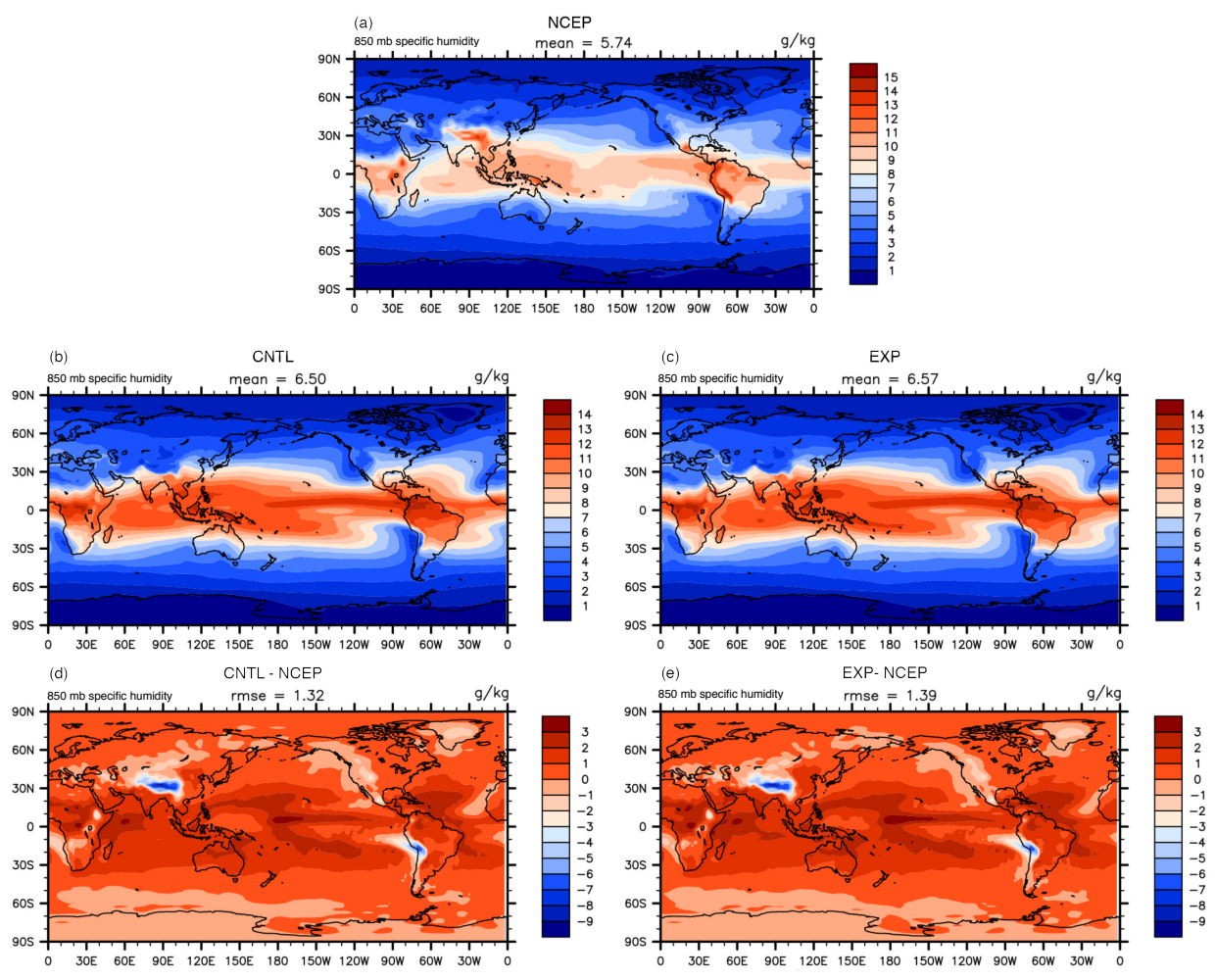

762 Figure A3. The spatial distribution of relative humidity at $850 \mathrm{hPa}$ in (a) observation,

763 (b) CNTL, (c) EXP, (d) CNTL minus observation, (e) EXP minus observation.

764

765

766

767

768 

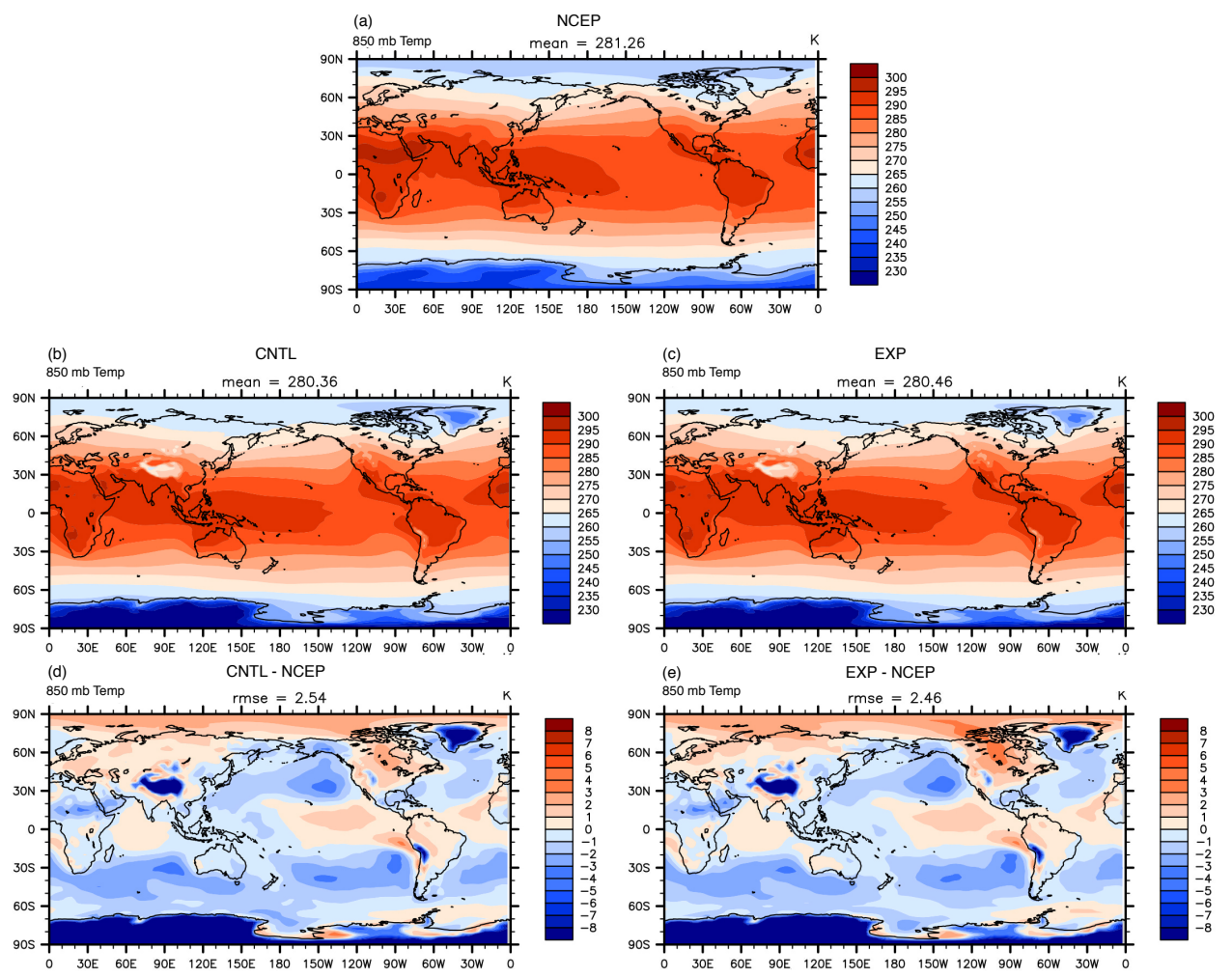

770 Figure A4. The spatial distribution of temperature at $850 \mathrm{hPa}$ in (a) observation, (b)

771 CNTL, (c) EXP, (d) CNTL minus observation, (e) EXP minus observation. 